Q. Fradet, M. Braun-Unkhoff, U. Riedel

A sectional approach for the entrained-flow gasification of slurry fuels, Energy Fuels 32 (2018) 12532-12544.

This document is the Accepted Manuscript version of a Published Work that appeared in final form in Energy Fuels, copyright $@$ A American Chemical Society after peer review and technical editing by the publisher. To access the final edited and published work see https://pubs.acs.org/articlesonrequest/AOR-Mf9T55jT5iBUZfEEKjrY

http://dx.doi.org/10.1021/acs.energyfuels.8b02785 


\title{
A sectional approach for the entrained flow gasification of slurry fuels
}

\author{
Quentin Fradet,* Marina Braun-Unkhoff, and Uwe Riedel \\ Institute of Combustion Technology, German Aerospace Center (DLR), Stuttgart, Germany \\ E-mail: quentin.fradet@dlr.de
}

\begin{abstract}
Energy densification is the overall objective of the on-going bioliq ${ }^{\circledR}$ project. Bioslurry, obtained via fast pyrolysis of low-grade biogenic resources, is converted into high quality syngas in a high pressure entrained flow gasifier. The modeling of this three-phase system involving high pressure and high temperature sub-processes is very challenging. The detailed representation of the chemical sub-processes goes along with an increase of the computational cost. In this work, a novel approach is developed to achieve fast and accurate Computational Fluid Dynamics (CFD) simulations of the gasification of a slurry fuel in a laboratory entrained flow gasifier under atmospheric pressure. The method investigated relies on a sectional approach to describe the char gasification. An Euler-Euler approach is used for the modeling of the slurry/gas phase system. Ethylene glycol is used to represent the liquid part of the slurry. Experimental data for validation are taken from various experiments (Fleck et al. 2018, Fleck et al. 2015) conducted at the laboratory Research Entrained flow GAsifier (REGA) at the Karlsruhe Institute of Technology.
\end{abstract}

\footnotetext{
${ }^{*}$ To whom correspondence should be addressed
} 


\section{Nomenclature}

\section{Adimensional numbers}

$\mathrm{Nu} \quad$ Nusselt number

Pr Prandtl number

Re Reynolds number

Sc Schmidt number

Sh Sherwood number

\section{Greek letters}

$\alpha \quad$ Volume fraction

$\eta \quad$ Particle number distribution w.r.t. molar weight

$$
\begin{array}{r}
{\left[(\mathrm{g} / \mathrm{mol})^{-2}\right]} \\
{\left[\mathrm{kg} / \mathrm{m}^{3} / \mathrm{s}\right]} \\
{[\mathrm{kg} / \mathrm{m} . \mathrm{s}]}
\end{array}
$$

$\Gamma \quad$ Rate of mass generation

$\mu \quad$ Dynamic viscosity

$\omega \quad$ Ratio representative of intra-class distribution

$\rho \quad$ Density

$$
\left[\mathrm{kg} / \mathrm{m}^{3}\right]
$$

$\sigma_{g} \quad$ geometric standard deviation

$\varepsilon_{\text {slurry }}^{\mathrm{EG}}$ Liquid volume fraction in the slurry droplet

\section{Roman letters}

$\dot{m} \quad$ Mass flow rate of phase change

$\dot{R} \quad$ Reaction rate 
v Velocity

$A$ pre-exponential factor of gasification reaction w.r.t. carbon conversion degree $\left[\mathrm{s}^{-1}\right]$

$A^{\prime} \quad$ Pre-exponential factor of gasification reaction w.r.t. concentration $\quad\left[1 /\left(\mathrm{s} \cdot \mathrm{bar}^{0.6}\right)\right]$

$B_{M} \quad$ Mass Spalding number

$D \quad$ Solid particle diameter

$D_{50} \quad$ Median diameter of the volume size distribution

$D_{84} \quad$ Particle size where $84 \%$ of the particles are smaller

$D_{v g} \quad$ Diffusion coefficient of vapor in gas

$E_{a} \quad$ Activation energy

$h \quad$ Heat transfer coefficient

$k \quad$ Thermal conductivity

$m \quad$ Particle mass distribution w.r.t. molar weight

$N_{3} \quad$ Cumulative particle size distribution by volume

$n_{3} \quad$ Particle size distribution by volume

$N_{A} \quad$ Avogadro number

$N_{c} \quad$ Number of class

$P \quad$ Pressure

$q \quad$ Mass fraction contained in a class 
T Temperature

V Volume

$X \quad$ Mole fraction

$x \quad$ Molar weight variable

$[\mathrm{g} / \mathrm{mol}]$

$X_{c} \quad$ Carbon conversion degree

$Y \quad$ Mass fraction

$y_{\text {slurry }}^{E G}$ EG mass percentage in the slurry droplet

$y_{\text {slurry }}^{\text {solid }}$ Solid mass percentage in the slurry droplet

\section{Indices}

$\infty \quad$ bulk gas

eff effective

$g \quad$ gas

$i \quad i^{t h}$ BIN class

$k \quad$ species

$l \quad$ liquid

ox oxidant

$p \quad$ phase (liquid or gas)

sat saturation

$v \quad$ vapor

\section{Acronyms}


BIN Sectional approach class

CFD Computational Fluid Dynamics

EFG Entrained Flow Gasification

EG Ethylene Glycol

LES Large Eddy Simulation

RANS Reynolds-Averaged Navier-Stokes

REGA Research Entrained flow GAsifier

SMD Sauter Mean Diameter

STP Standard Temperature and Pressure

\section{Introduction}

The interest for gasification has increased worldwide. ${ }^{1}$ On one side in the coal industry, as a more efficient method for chemical and power production and on the other side with the emergence of biomass based renewable energy. In particular, entrained flow gasification (EFG) is the rising technology, due to its fuel flexibility, its reduced tar and soot production, and its high carbon conversion rate. ${ }^{2}$ In these gasifiers, operated at high temperature and pressure, the fuel, that can be a solid, a liquid or a slurry, is fed in simultaneously with the oxidant.

The bioliq ${ }^{\circledR}$ project $^{3}$ relies on a two-step process. The first decentralized step of fast pyrolysis produces a bio-slurry made of pyrolysis oil and char. This slurry fuel, of higher energy density, is then collected and transported to a central plant where its gasification in a high pressure entrained flow gasifier produces syngas. The design and scale-up of industrial gasification plants were mainly based on experience, as stated by Fleck et al., ${ }^{4}$ 
because the knowledge gaps ${ }^{5}$ are numerous for the modeling of such multiphase reacting system. The atmospheric lab-scale gasifier REGA ${ }^{4}$ is used to generate experimental data for the modeling of the sub-processes. In this experimental gasifier, ethylene glycol (EG) is used as a surrogate for pyrolysis oil. As it has been shown, ${ }^{6}$ EG has physical-chemical characteristics similar to pyrolysis oil from various feedstocks, such as its viscosity, its density or its enthalpy of combustion. The reactor is fed with either only EG (liquid fuel) or with EG and biogenic char particles (slurry fuel). Early work presenting RANS (Reynolds-Averaged Navier-Stokes) simulation for the modeling of REGA using a detailed chemistry mechanism was performed by Hafner et al. ${ }^{7}$ Two papers on numerical simulations on RANS ${ }^{8}$ and LES (Large Eddy Simulation) ${ }^{9}$ are documented in the literature along with the experimental data set. ${ }^{4}$ The simulations mentioned above, as well as other examples of simulations of entrained flow gasifiers, ${ }^{10-13}$ rely on the conventional Lagrangian particle tracking method for the dispersed phase modeling. In this approach, discrete fluid parcels representing fuel droplets or fuel particles are followed in time and provide point sources for the gas field. This multiphasic Euler-Lagrange approach is usually adopted because of the low volume fraction of the dispersed phase. However, this approach presents limitations when it comes to the modeling of slurry fuels. On the one hand, some assumptions are required. As the liquid evaporation is faster than the solid conversion, it is usually assumed that each fuel particle is made of a solid core surrounded by liquid. In this way, the liquid evaporation occurs first and when the amount of liquid in the particle is negligeable, the solid conversion is taken into account. This is a simplification of the thermo-physical phenomena where slurry droplets contain a wide solid particle size distribution that are released continuously during the liquid evaporation. On the other hand, high computational costs arise from the high particle loading and from time-scales differing by several orders of magnitude. Typical chemical time scale of the gas phase fuel oxidation are between $10^{-10} \mathrm{~s}$ and $10^{-3} \mathrm{~s}^{14}$ The liquid evaporation of one slurry fuel droplet is a fast process, between $10^{-3} \mathrm{~s}$ and $10^{-1} \mathrm{~s}$, but the residence time of the solid content in the reactor is high and can exceed $10 \mathrm{~s}$. Concerning 
the particle loading and taking into account the data set ${ }^{15}$ used in the present work from the laboratory scale gasifier REGA with a solid mass flow rate of about $1.25 \mathrm{~kg} / \mathrm{h}$ and a particle mean diameter of $22 \mu \mathrm{m}$, the loading exceeds $10^{7}$ particles per second entering the reactor. This number is an underestimate if we consider smaller particles or the case of an industrial gasifier.

In this work, a novel approach is proposed as an alternative to the common method in order to overcome the limitations that have been presented. The liquid or slurry fuel injected is considered in an Euler-Euler frame with the gas phase. After the liquid evaporation, the solid particles are described by gas phase transport equations, which are based on mass classes via the so-called sectional approach. A reaction scheme with kinetic rates is proposed for the solid devolatilization and gasification. If an Euler-Euler approach for the modeling of an entrained flow gasifier has already been proposed by Vicente et al., ${ }^{16}$ it is important to point out the differences in its application. In their work, the Eulerian-Eulerian concept is used in the case of coal gasification, and both the gas and particulate phases are solved with Eulerian conservation equation. In contrast, the multiphase modeling in the present case deals with the liquid or slurry spray modeling. The solid conversion (devolatilization, heterogeneous reactions) is handled in the gas frame by means of a sectional method, which is, to the authors' knowledge, used for the first time.

This paper is organized as follows: in section 2 we will present the Euler/Euler approach to model liquid gasification fuels; ethylene glycol as a surrogate for pyrolysis oil in our case. The evaporation model, as well as the reaction model, are described. Section 3 introduces the sectional approach for gasification (size dependent reaction kinetics) to account for solid particles in the fuel to be gasified, thus extending the concept presented in the previous chapter to include slurry fuels. Section 4 presents the modeling and simulation results for 3 different gasification experiments documented with sufficient details to be used as reference cases for entrained flow gasification at conditions typical to the bioliq ${ }^{\circledR}$ process. ${ }^{3}$ 


\section{Modeling liquid or slurry fuels in the gas phase}

Entrained flow gasifiers are fed through an injector with the gasification agent and the liquid or slurry fuel (liquid and solid). This section is dedicated to the presentation of the EulerEuler approach to model the spray behavior, with a particular interest in the mass and heat transfer modeling.

\section{$2.1 \quad$ Euler-Euler approach}

The open-source CFD software OpenFOAM ${ }^{17}$ has been used in this work. The multiphase Euler-Euler solver called reactingTwoPhaseEulerFoam has been used as a basis and has been modified for the present work. The Euler-Euler approach relies on defining the gas phase and the liquid phase through their respective volume fraction $\alpha$. The mass conservation equation for each of the phases $p$, based on their respective density $\rho$, is written as:

$$
\frac{\partial \alpha_{p} \rho_{p}}{\partial t}+\nabla \cdot\left(\alpha_{p} \rho_{p} \mathbf{v}_{p}\right)=\Gamma_{p}
$$

The term $\Gamma_{p}$ represents the rate of mass generation of phase $p$ at the interface. The sum of the volume fraction must satisfy the closure condition

$$
\alpha_{l}+\alpha_{g}=1
$$

The gas phase is a multi-component and reacting phase. Each species satisfies the trans-

port equation given by equation 3 . The second phase is non reacting (reaction rate $\dot{R}_{k}=0$ ) and can be a single component phase if the fuel is only ethylene glycol or a multi-component phase in the case of a slurry fuel. In this second case, each species is described by its transport equation.

$$
\frac{\partial \alpha_{p} \rho_{p} Y_{k}}{\partial t}+\nabla \cdot\left(\alpha_{p} \rho_{p} \mathbf{v}_{p} Y_{k}\right)=\nabla \cdot\left(\alpha_{p} \frac{\mu_{e f f}}{\mathrm{Sc}_{p}} \nabla Y_{k}\right)+\alpha_{p} \dot{R}_{k}+\frac{\dot{m}_{k}}{V}
$$


where $\dot{m}_{k}$ is the mass flow rate of the species $k$ that undergoes a phase change. The solver is able to identify in each cell which of the phase is continuous and which phase is dispersed. In the case of entrained flow gasification, the liquid or the slurry fuel is always the dispersed phase. Therefore, the value of $\dot{m}_{k}$ is zero for all species except for EG that undergoes evaporation and for the solid that enters the gas phase.

\subsection{Ethylene glycol evaporation and reaction}

This section presents the evaporation modeling for ethylene glycol. Slurry fuels and the char particles contain therein will be treated in section 3.1.

The widely used Spalding's evaporation rate $\dot{m}^{18}$ is defined as:

$$
\dot{m}=2 \pi R \text { Sh } D_{v g} \rho_{g} \ln \left(1+B_{M}\right)
$$

where Sh is the Sherwood number, a dimensionless number which represents the ratio of convective to diffusive mass transport. $R, D_{v g}$ and $\rho_{g}$ are respectively the droplet radius,

the vapor diffusivity in the mixture and the density of the gaseous mixture. $B_{M}=\frac{Y_{v, s a t}-Y_{v, \infty}}{1-Y_{v, s a t}}$ is the mass Spalding number. This number is calculated from:

$$
\begin{gathered}
Y_{v, s a t}=\frac{M_{v} X_{v, s a t}}{M_{v} X_{v, s a t}+\left(1-X_{v, s a t}\right) M_{\infty}}, \\
X_{v, s a t}=X_{l} \frac{P_{s a t}\left(T_{l}\right)}{P_{\infty}} .
\end{gathered}
$$

The so-called film theory that takes into account the convective transport caused by the droplet motion relative to the gas ${ }^{19}$ has been neglected in this work. The one third rule has been applied for the gas film temperature as often recommended in the literature. ${ }^{20}$ The Sherwood number correlation

$$
\mathrm{Sh}=1+(1+\operatorname{Re} \mathrm{Sc})^{1 / 3} \max \left(1, \operatorname{Re}^{0.077}\right)
$$


has been taken from Clift et al., ${ }^{21}$ where Re and Sc are respectively the Reynolds number and the Schmidt number. The convective heat transfer coefficient $h$ is determined via the Nusselt number $\mathrm{Nu}$.

$$
h=\frac{\mathrm{Nu} k_{g}}{2 R}
$$

$k_{g}$ is the thermal conductivity of the gas and the corresponding correlation from Clift et al. ${ }^{21}$ for $\mathrm{Nu}$, depending on the Reynold and the Prandtl number Pr, is used:

$$
\mathrm{Nu}=1+(1+\operatorname{RePr})^{1 / 3} \max \left(1, \operatorname{Re}^{0.077}\right)
$$

The aforementioned expression describes the mass transfer for one spherical droplet. It can be extended to find the mass flow rate per volume which leads to

$$
\frac{\dot{m}}{V}=\frac{3}{2} \frac{\alpha_{l}}{R^{2}} \text { Sh } D_{v g} \rho_{g} \ln \left(1+B_{M}\right)
$$

This approach allows the simulation of the surrogate of the pyrolysis oil, ethylene glycol, and its evaporation. It relies nevertheless on some assumptions. The diameter of the droplets is kept constant, while the evolution of the real diameter depends on physico-chemical properties (droplet break-up and atomization) and on mass transfer (evaporation). The diameter for the droplet size was taken at $70 \mu \mathrm{m}$ according to the measurement of Fleck et al. ${ }^{4}$ that found an SMD between 60 and $80 \mu \mathrm{m}$. The heat capacity is also kept constant. Nonetheless, sufficient accuracy is expected for the reproduction of the jet multiphase flow, and, in addition with the Eulerian approach for the char gasification, a global speed up in terms of calculation time in comparison to the usual Lagrangian approach is foreseen.

The reactions of ethylene glycol in the gas phase are computed (source term $\dot{R}_{k}$ ) based on a detailed mechanism discussed in detail by Kathrotia et al. ${ }^{6}$ This reaction scheme describes the decomposition of ethylene glycol, the formation of intermediate species and subsequent reactions to hydrogen, carbon monoxide, and the stable products $\mathrm{CO}_{2}$ and $\mathrm{H}_{2} \mathrm{O}$. For efficient 
use in the 2-dimensional gasifier simulation, the mechanism has been optimized (number of species reduced to 23) using the method described by Methling et al. ${ }^{22}$

Standard models already implemented in OpenFOAM (version 5.0) have been used as such. The standard $k-\epsilon \operatorname{model}^{23}$ have been chosen for the turbulence modeling. The P1 model $^{24}$ for the radiation has been used. Finally, the turbulence-chemistry interaction has been modeled by the PaSR (Partially Stirred Reactor) combustion model. ${ }^{25}$

\section{Char gasification using a sectional approach}

\subsection{Char description with discrete classes}

The concept of the sectional approach, or discrete approach, consists in the division of the mass range of interest into a certain number of classes, $N_{c}$. These classes are also denoted as BIN classes or BINs. The geometric constraint of Gelbard et al. ${ }^{26}$ requires a scaling factor superior or equal to 2 between two successive classes. As commonly used, ${ }^{27-30}$ a scaling factor of 2 has been chosen in this work. Originally developed for aerosol description, this method has been applied to soot modeling by Pope and Howard ${ }^{27}$ and has later been widely re-used. ${ }^{31-33}$ This model has more recently found application in the CFD field. ${ }^{28,29,34-36}$ Computationally less expensive than very detailed soot modeling, ${ }^{37,38}$ the sectional approach provides a good accuracy. Di Domenico ${ }^{34}$ used for the first time the sectional approach for the CFD simulation of soot formation in gas turbine combustors. This approach was nevertheless restricted to the description of the Polycyclic Aromatic Hydrocarbons (PAHs), or soot precursors. A simpler two-equation model was employed for the soot particle dynamics. Blacha et al. ${ }^{28}$ expanded the sectional approach for PAH and soot species. The field of application were simulations of laminar flames and good prediction of soot volume fractions for a variety of fuels were achieved. Thanks to the increase of computational capabilities during recent years, the state of the art includes large eddy simulations (LES) of sooting turbulent jet flames ${ }^{36}$ with a sectional approach for both PAH (3 classes) and soot (24 classes). 
In the present work, an attempt to apply the sectional approach in the case of char gasification is made for the first time. The objective is to achieve the modeling of slurry fuel gasification and its implementation in CFD simulations of the entrained flow gasifier REGA. For this purpose, experiments from Fleck et al. ${ }^{15}$ are exploited. The operating conditions will be detailed in the results section; the analysis of the char obtained from straw pyrolysis that has been conducted ${ }^{15}$ will be used as a support for the presentation of the modeling. However, the reasoning that is conducted can be achieved with any source of biomass based char. The median value of the volume size distribution has been determined to be $D_{50}=22.3 \mu \mathrm{m}$. This number divides the particles population in two equal parts with respect to the volume. Data has been delivered by KIT $^{39}$ that shows solid particle size distributions. More information about the condition of pyrolysis and the method of analysis used can be found in Pfitzer et al. ${ }^{40}$ The data showed that the particle size distributions follow a log-normal distribution. The volume distribution function $n_{3}(D)$ can be expressed ${ }^{41}$ according to equation (11) below.

$$
n_{3}(D)=\frac{1}{\sqrt{2 \pi} D \ln \sigma_{g}} \exp \left[-\frac{1}{2}\left(\frac{\ln \left(D / D_{50}\right)}{\ln \sigma_{g}}\right)^{2}\right]
$$

$\sigma_{g}$, the geometric standard deviation, is defined as the ratio $D_{84}$ over $D_{50}$. Similarly to $D_{50}, D_{84}$ is the diameter for which the cumulative volume of the particles with diameter smaller than $D_{84}$ accounts for $84 \%$ of the total volume. One data $\operatorname{set}^{39}$ shows a median number of $D_{50}=22.33 \mu \mathrm{m}$, in agreement with the value in Fleck et al. ${ }^{15} D_{84}$ has been determined with this data set with a value of $40 \mu \mathrm{m}$. The corresponding curve for $n_{3}$ as a function of the diameter is shown in Fig. 1, as well as the cumulative function $N_{3}$.

In the sectional approach, each BIN class is defined through a lower and an upper molar weight, with a ratio or scaling factor between both values equal to 2 . The variable of interest is therefore the molar weight. By assuming the particle density independent of its size, the mass distribution function is the same as the volume distribution function. Since the functions have been normalized, the mass distribution function according to the molar weight 


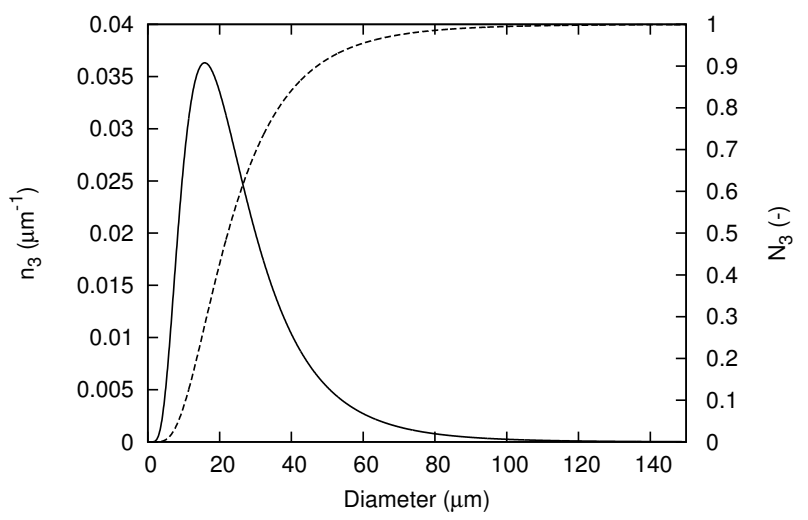

Figure 1: Volume distribution function and cumulative function versus particle diameter

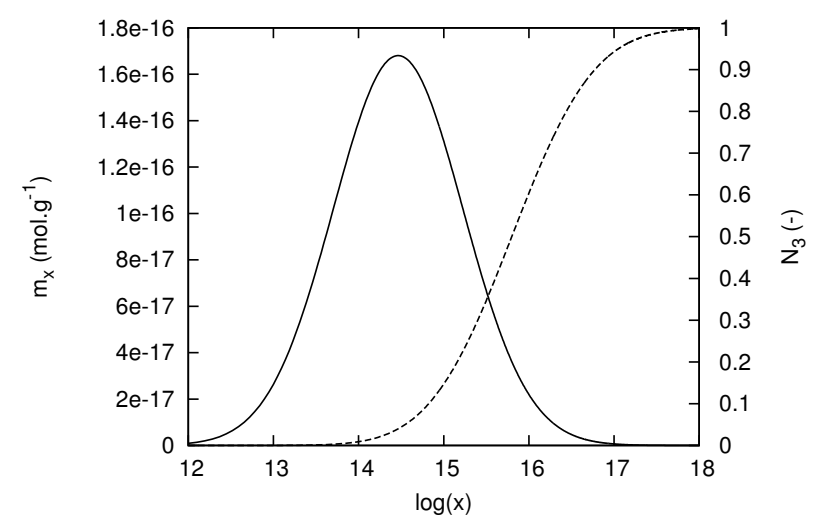

Figure 2: Mass distribution function and cumulative function versus logarithm of molar weight

can be written as:

$$
\begin{gathered}
m(x)=\frac{d N_{3}}{d x}=\frac{d N_{3}}{d D} \frac{d D}{d x}=n_{3} \frac{d D}{d x}, \\
m(x)=\frac{1}{\sqrt{2 \pi} \ln \sigma_{g} 3 x} \exp \left[-\frac{1}{2}\left(\frac{\frac{1}{3} \ln \left(\frac{6 x}{\rho N_{A} \pi}\right)-\ln \left(D_{50}\right)}{\ln \sigma_{g}}\right)^{2}\right] .
\end{gathered}
$$

The corresponding curves for the mass distribution function and the cumulative function are displayed in Fig. 2.

Discrete classes have to be created based on this continuous mass distribution. That means, bounds have to be chosen to limit the number of classes. The lower limit of the first class is defined as the point where $N_{3}=0.01$. Thus, the first class comprises the 
particles whose molar weight is in the intervall $\left[1.11 \cdot 10^{14}-2.22 \cdot 10^{14}\right] \mathrm{g} / \mathrm{mol}$, the second class $\left[2.22 \cdot 10^{14}-4.44 \cdot 10^{14}\right] \mathrm{g} / \mathrm{mol}$, and so on. The total number of classes, $N_{c}$, is defined as the smallest integer that reaches $N_{3}\left(M_{B I N 1}^{\min } \cdot 2^{N_{c}}\right)>0.99$. It gives the $12^{\text {th }}$ and last class defined within the bounds $M_{B I N 12}^{\min }=2.27 \cdot 10^{17} \mathrm{~g} / \mathrm{mol}$ and $M_{B I N 12}^{\max }=4.54 \cdot 10^{17} \mathrm{~g} / \mathrm{mol}$. The mass fraction contained in each of the classes follows

$$
q_{i}=\int_{M_{\mathrm{BIN}}}^{M_{\mathrm{BIN}}^{\min }} m(x) d x
$$

These values are then normalized to enclose all the mass; they are displayed in Fig. 3.

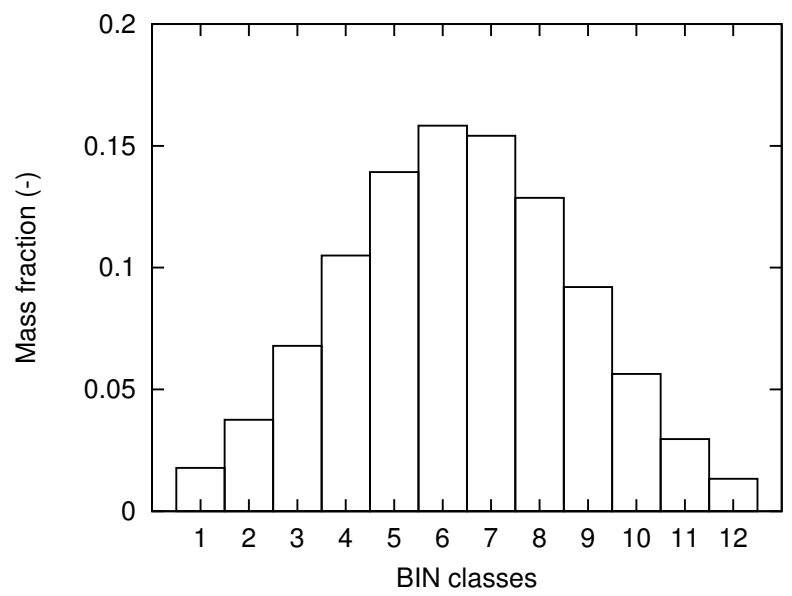

Figure 3: Mass fraction of the different BIN-classes

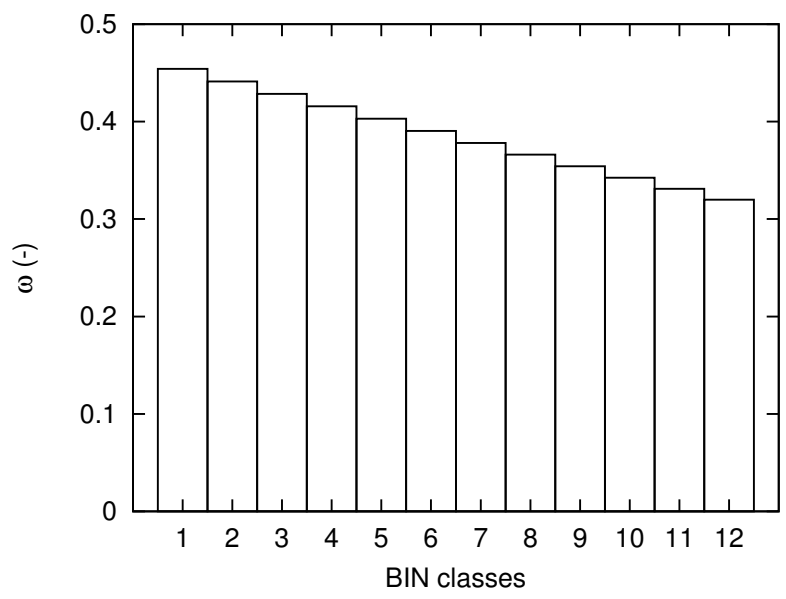

Figure 4: Ratio representative of the intra-sectional distribution 
In the sectional approach for the soot modeling, one assumption has to be made concerning the intra-BIN distribution. There exist several possibilities. For example, the number distribution, defined as $\eta(x)=\frac{m(x)}{x}$, can be considered constant within a class, then $m(x)=$ const. $\cdot x$. Or the mass distribution is constant and $\eta(x)=\frac{\text { const. }}{x}$. In the current case, these distributions are perfectly known through equation 13 . This is a real asset for the accuracy of the modeling because it allows the determination of the mean molar weight of each class:

$$
M_{i}^{\text {mean }}=\frac{\int_{M_{\mathrm{BIN}_{i}}^{m i n}}^{M_{\mathrm{IIN}}^{\max }} m(x) d x}{\int_{M_{\mathrm{BIN} i}^{m i n}}^{M_{\mathrm{BIN}}^{m a x}} \eta(x) d x} .
$$

The ratio $\omega=\frac{M_{i}^{\text {mean }}-M_{i}^{\text {min }}}{M_{i}^{\text {max }}-M_{i}^{\text {min }}}$ is representative of the $i^{\text {th }}$ intra-class distribution. This ratio is represented for each class in Fig. 4. A value of 0.5 corresponds to a constant number distribution within a class while a value of $1 / \ln (2)-1 \simeq 0.44$ corresponds to a constant mass distribution. As it can be seen, the first classes are close to the case of a constant mass distribution. Then, the ratio drops below 0.4. This indicates that the number density of particles drops quickly within each class. The successive steps presented so far have allowed describing the experimental straw char particles distribution with a sectional approach based on the knowledge of $D_{50}$ and $D_{84}$ only (no further assumptions needed).

\section{$3.2 \quad$ Reaction scheme}

A 2-step scheme, from char to secondary char to ash (see Fig. 5) has been chosen to represent the evolution of the char inside the reactor. This is in agreement with the model used at the Karlsruhe Institute of Technology ${ }^{42}$ (KIT), where early CFD simulations of slurry-fed entrained flow gasifier at 40 bar were perfomed in order to identify typical droplets conversion paths. This was further detailed by Kolb et al. ${ }^{5}$ After the evaporation of the liquid, the char particles enter the gas phase and lose mass due to their thermal degradation. This step, also denoted secondary pyrolysis because it corresponds to the pyrolysis of char originating 
from the pyrolysis of biomass, is fast and endothermic. This mass loss will be defined as the volatile part of the char. It also includes the moisture of the char. The second part of the scheme concerns the gasification of the secondary char. Carbon dioxide, as well as steam, will react through heterogeneous reactions with char ${ }^{43}$ to form carbon monoxide and hydrogen. The non-reacting part of the particles, ash, is obtained once the gasification is complete. The objective of this section is to choose appropriate species properties for the secondary char and ash, as well as to find the stoichiometric coefficients and kinetic rates for the reactions linking these species.

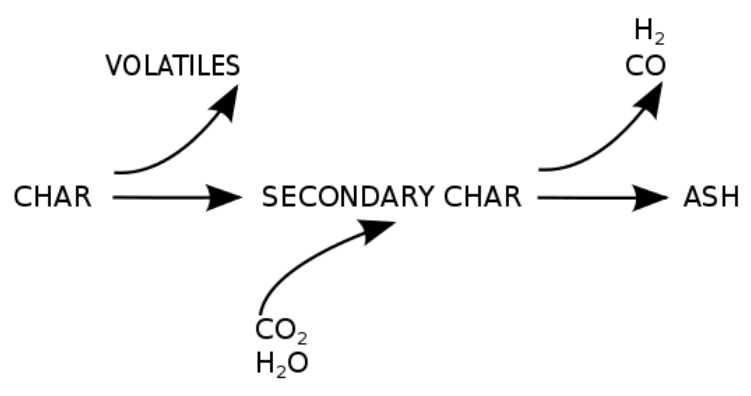

Figure 5: Global char reaction scheme

Ultimate analysis and proximate analysis of the char are reported ${ }^{15}$ and reproduced in Table 1.

Table 1: Ultimate and proximate analysis of straw char.

\begin{tabular}{lcccc}
\hline Ultimate analysis (water and ash free) & $\mathrm{C}$ & $\mathrm{H}$ & $\mathrm{O}$ & $\Sigma_{\mathrm{N}, \mathrm{S}, \mathrm{Cl}}$ \\
\hline Element $\left[\%_{\text {mass }}\right]$ & 85.59 & 3.92 & 9.12 & 1.363 \\
\hline & Moisture & Ash & Volatiles & $C_{\text {fix }}$ \\
\hline Proximate analysis & 1.9 & 17.9 & 14.6 & 65.6 \\
\hline Composition $\left[\%_{\text {mass }}\right]$ & & & &
\end{tabular}

The proximate analysis provides the average composition of the primary char in terms of fixed carbon, volatiles, moisture and ash. As mentioned earlier, moisture is considered as part of the volatiles in the model. it is assumed that each particle of straw char has originally 
the same composition given by the proximate analysis. It means that two other groups of BIN-classes can be created in relation to the first group such that

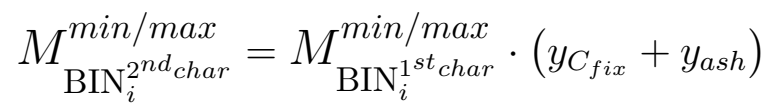

and

$$
M_{\mathrm{BIN}_{i}^{\text {ash }}}^{\min / \max }=M_{\mathrm{BIN}_{i}^{1 s t} \text { char }}^{\text {min } / \max } \cdot y_{\text {ash }}
$$

Experiments have been conducted at $\mathrm{KIT}^{44}$ to determine the reaction kinetics of the secondary pyrolysis and of the gasification of the secondary char with $\mathrm{CO}_{2}$. Concerning the secondary pyrolysis, char originating from the fast pyrolysis of bark-less soft wood has been injected in the drop-tube reactor VERA. This feedstock was injected with varying temperature into the reactor, ranging from 1073 to $1873 \mathrm{~K}$ and the residence time was kept constant at $200 \mathrm{~ms}$. The elemental composition of the secondary char obtained shows a completion of the secondary pyrolysis reaction at $1473 \mathrm{~K}$ and above. Beyond this temperature, the char is composed almost of pure carbon and ash. As the temperature of the REGA reactor is above $1473 \mathrm{~K}$, the secondary char composition is chosen to be pure carbon and ash. This information is reported in the third column in Table 2. The proximate analysis, ash free, can also be seen in the first column. Now, with the knowledge of the proximate analysis of the straw char and the chemical composition of both the straw char and the secondary char, the calculation of the volatile composition through mass and elemental balances can be achieved. The results obtained can be seen in the fourth and fifth column in Table 2 in term of mass and volume percentage. However, the proximate analysis is achieved at a temperature of only $1173 \mathrm{~K}$. And as it has been observed in the experiments in the VERA reactor, ${ }^{44}$ the secondary pyrolysis is not complete at this temperature. Therefore, it is very likely that the fraction of volatiles is underestimated. This has an influence on the calculated elemental composition, the proportion of hydrogen and oxygen being overestimated. The fraction of volatiles in the primary char is dependent of the source of biomass and the condi- 
tion of the fast pyrolysis. ${ }^{45}$ Straw char, obtained at the same conditions in a screw pyrolysis reactor, ${ }^{46}$ has been pyrolyzed a second time at $1473 \mathrm{~K} .{ }^{47}$ Thus, this secondary pyrolysis can be considered as complete. They measured at the outlet of the reactor $30 \%$ vol $\mathrm{CO}$, $2 \%$ vol $\mathrm{CH}_{4}$ and $68 \%$ vol $\mathrm{H}_{2}$ in dry basis. These values differ from those calculated previously and they allow calculating a value of $19 \%$ mass of volatiles instead of $14 \%$ mass. Even if the difference in term of mass is not very important, the elemental composition of the volatiles changes greatly as seen in Table 2. The representative species for the volatile matter can then be more appropriately chosen. Both cases have been studied in the present work to see the influence of the volatile mass fraction and composition. In the first case (deduced from proximate analysis), the following species have been chosen to represent the volatiles $\mathrm{Vol}=\left\{\mathrm{CO} ; 2 \mathrm{CH}_{4} ; 4 \mathrm{H}_{2} \mathrm{O} ; 7 \mathrm{H}_{2}\right\}$, while in the other case (deduced from secondary pyrolysis experiment), $\mathrm{Vol}=\left\{\mathrm{EG} ; \mathrm{CO} ; \mathrm{CH}_{4} ; \mathrm{H}_{2} \mathrm{O} ; 3 \mathrm{H}_{2}\right\}$ has been chosen. These sets of species are later used in the reaction mechanism of char pyrolysis presented below.

Table 2: Elemental composition of the primary and secondary char and of the volatile part.

\begin{tabular}{lccccc}
\hline & $\begin{array}{c}\text { Straw char (af) } \\
\text { Exp. }\end{array}$ & $\begin{array}{c}\text { Secondary char (af) } \\
\text { Exp. (approx.) }\end{array}$ & $\begin{array}{c}\text { Volatiles }^{a} \\
\text { Calc. }\end{array}$ & $\begin{array}{c}\text { Volatiles }^{\text {a }} \\
\text { Calc. }\end{array}$ & $\begin{array}{c}\text { Volatiles }^{b} \\
\text { Exp. }\end{array}$ \\
\cline { 2 - 6 } Element & {$\left[\%_{\text {mass }}\right]$} & {$\left[\%_{\text {mass }}\right]$} & {$\left[\%_{\text {mass }}\right]$} & {$\left[\%_{\text {vol }}\right]$} & {$\left[\%_{\text {vol }}\right]$} \\
\hline $\mathrm{C}$ & 84.8 & 100.0 & 24.2 & 7.8 & 15.5 \\
$\mathrm{H}$ & 4.1 & 0.0 & 20.6 & 78.9 & 69.9 \\
$\mathrm{O}$ & 11.1 & 0.0 & 55.2 & 13.3 & 14.6 \\
$\Sigma$ & 100.0 & 100.0 & 100.0 & 100.0 & 100.0 \\
\hline
\end{tabular}

${ }^{a}$ From proximate analysis.

${ }^{b}$ From secondary pyrolysis experiment

In summary, in the paragraphs above discrete classes for the primary char, the secondary char and for ash have been created and the volatile content has been characterized. Now, the next step consists in determining the reactions linking the species and the corresponding stoichiometric coefficients. The reaction for a particle that belongs to the $i^{\text {th }}$ class of the primary char group can be written as: 


$$
\mathrm{BIN}_{i}^{1^{\text {st }} \text { char }} \longrightarrow c_{1} \mathrm{BIN}_{i}^{2^{\text {nd }} \text { char }}+c_{2} \mathrm{Vol}
$$

The assumption that each particle of one class from the primary char gives one particle of the corresponding class of the secondary char allows to set $c_{1}=1$, and the mass balance of the secondary pyrolysis reaction leads to:

$$
c_{2}=\frac{M_{\mathrm{BIN}_{i}^{1 t_{c h a r}}}^{\text {mean }}-M_{\mathrm{BIN}_{i}^{\text {nd }}}^{\text {meanar }}}{M_{\mathrm{Vol}}} .
$$

Unfortunately, the experiments that have been carried out ${ }^{44}$ do not offer kinetic rates for the secondary pyrolysis of primary char, only equilibrium data have been obtained. The information available is that the reaction is completed before $200 \mathrm{~ms}$. Therefore, an uncertainty analysis will be conducted in the results section to determine the effect of the kinetic rate of this reaction and to define a plausible value.

Similar to the approach used in equation 18 , the gasification reactions are written as:

$$
\begin{gathered}
\mathrm{BIN}_{i}^{2^{\text {nd }} \text { char }}+c_{3} \mathrm{CO}_{2} \longrightarrow \mathrm{BIN}_{i}^{a s h}+2 \cdot c_{3} \mathrm{CO}, \\
\mathrm{BIN}_{i}^{2^{\text {nd }} \text { char }}+c_{3} \mathrm{H}_{2} \mathrm{O} \longrightarrow \mathrm{BIN}_{i}^{a s h}+c_{3} \mathrm{CO}+c_{3} \mathrm{H}_{2}
\end{gathered}
$$

where

$$
c_{3}=\frac{M_{\mathrm{BIN}_{i}^{2 n d} \text { char }}^{\text {mean }}-M_{\mathrm{BIN}_{i}^{a s h}}^{\text {mean }}}{M_{\mathrm{C}}} .
$$

Studies on the reactivity of coal char gasification are extensively documented. ${ }^{48,49}$ However, the literature concerning the gasification of biomass based char is sparse in comparison. However, Di Blasi ${ }^{50}$ gave a review on the state-of-the-art of the gasification of lignocellulosic char including kinetic rates for reactions with carbon dioxide and steam. Most of the studies are based on thermogravimetric analysis (TGA) or pressurized TGA (pTGA). A great number of reaction rates are proposed because of the variety of the feedstock. However, all experiments show that the gasification does not occur below $1000 \mathrm{~K}$. The high activation en- 
ergies are in the range 180-250 kJ/mol. A pTGA and a free-fall fixed-bed (FFB) experiment with carbon dioxide are reported by Schneider et al. ${ }^{44}$ This experiment is particularly useful for the case considered here, because the sample utilized is the secondary char obtained from the experiment in the VERA reactor at $1873 \mathrm{~K}$. They obtained the following reaction rate

$$
r_{p T G A}=A \exp \left(\frac{-E_{a}}{R T}\right)=5.24 \cdot 10^{8} \exp \left(\frac{-236000}{R T}\right),
$$

The pre-exponential factor was not explicitly given but were deduced from Fig. $5 .{ }^{44}$ The reaction rate of the pTGA analysis is expressed in the form ${ }^{51}$

$$
r_{p T G A}=\frac{d X_{c}}{d t}
$$

where $X_{c}=\frac{m_{C_{0}}-m_{C}(t)}{m_{C_{0}}}$ is the carbon conversion degree. This reaction rate can also be expressed through the rate of mass loss

$$
-\frac{d m_{C}}{d t}=m_{C_{0}} A \exp \left(\frac{-E_{a}}{\bar{R} T}\right) .
$$

However, this particular experiment was carried out at 40 bar in the presence of $80 \% \mathrm{vol}$ carbon dioxide, thus could be used directly for the modeling of a high pressure gasifier. But in the case of REGA, at atmospheric pressure, the pressure of carbon dioxide and steam is much lower. The literature ${ }^{50}$ shows a dependency on the pressure of oxidant. A value of 0.6 for the order is chosen, in agreement to experiments. ${ }^{51}$

The rate of the gasification reaction is the rate at which all the carbon of a particle is converted. This can be linked with the rate obtained from the pTGA via a first order reaction rate

$$
r_{\text {gasification }}=-\frac{d\left[\mathrm{BIN}_{i}^{2^{n d} \text { char }}\right]}{d t}=A^{\prime} \exp \left(\frac{-E_{a}}{\bar{R} T}\right)\left[\mathrm{BIN}_{i}^{2^{n d} \text { char }}\right] P_{o x}^{0.6},
$$

where $E_{a}=-236 \mathrm{~kJ} / \mathrm{mol}$ and $A^{\prime}=6.55 \cdot 10^{7} 1 /\left(\mathrm{s} \cdot \mathrm{bar}^{0.6}\right)$. Therefore, the value of the 
activation energy has been kept identical to the measured value by the $\mathrm{pTGA}^{44}$ and the pre-exponential factor has been chosen to take into account the oxidant partial pressure in the gasifier REGA at atmospheric pressure, $A^{\prime}=A / P_{o x}^{0.6}$.

The reasoning conducted so far has yielded to the description of the char inside slurry droplets and then to the successive steps that each char particle undergoes in the gas phase by means of reaction paths and kinetic rates.

In addition, a few modifications for the case with ethylene glycol containing char particles have to be made in the CFD code. One transport equation is added for each BIN class created, so $3 \cdot N_{c}$ for the gas phase according to the three groups of classes, the primary char, the secondary char and the ashes. $N_{c}$ species are also added for the liquid phase concerning the primary char injected with EG. The initial mass fractions for each of the species in the liquid phase are also given as input according to the values of Fig. 3. The evaporation is slightly modified to account for the presence of the solid in the liquid. As first mentioned by Lee et al., ${ }^{52}$ the liquid evaporation is dependent of the liquid in contact with the surface of the droplet and can be linked with the ethylene glycol volume fraction $\varepsilon_{\text {slurry }}^{\mathrm{EG}}$ inside the slurry droplet:

$$
\dot{m}_{\text {slurry }}^{\mathrm{EG}}=\dot{m}_{\text {pure }}^{\mathrm{EG}} \cdot \varepsilon_{\text {slurry }}^{\mathrm{EG}} .
$$

The rate of transfer of the primary char from the liquid to the gas phase is deduced from the fact that once a droplet is totally vaporized, all the solid should be considered in the gas phase. It has therefore been assumed that the mass transfer of solid from the liquid to the gas phase is proportional to the total mass transfer:

$$
\dot{m}_{\mathrm{BIN}_{i}^{11_{\text {char }}}}=q_{i} \cdot y_{\text {slurry }}^{\text {solid }} \cdot \dot{m}_{\text {slurry }}^{\text {tot }}=q_{i} \cdot y_{\text {slurry }}^{\text {solid }} \cdot \frac{\dot{m}_{\text {slurry }}^{\mathrm{EG}}}{y_{\text {slurry }}^{\text {EG }}},
$$

where $q_{i}$ is the already determined mass fraction of solid in the class $i$ (see Fig. 3). $y_{\text {slurry }}^{\text {solid }}$ and $y_{\text {slurry }}^{E G}$ are respectively the mass fraction of solid and of ethylene glycol in the slurry 
droplet. In the end, the need for implementation in the CFD code of the sectional method for char gasification is reduced. Most of the work concerns the pre-processing process, creation of pseudo-species and development of a mechanism based on them. Then, the pseudo-species are simply followed by classical transport equations (equation 3). What needs to be modified concerns the mass transfer treatment that is presented above in equation 26 and 27. For this reason, it is totally foreseeable to combine traditional Euler-Lagrange approach for the slurry droplets and sectional approach for the char gasification.

\section{Results}

Throughout this section and for representation purpose, the results from the simulation have been mirrored along the axis of symmetry. Section 4.1 will present the gasifier REGA built at KIT and data sets that have been published: Glycol, GSKS10 and REGA-glycol-T1. Section 4.2 will be dedicated in reproducing the data REGA-glycol-T1 for the validation of the employed method for the ethylene glycol gasification. While section 4.3 will report the simulation of test case Glycol and GSKS10 in order to study slurry fuels (the effect of the addition of char particles to the fuel).

\subsection{REGA experiments}

Experiments were carried out in the atmospheric pilot scale entrained flow gasifier REGA (Research Entrained flow GAsifier). The process flow sheet of this reactor can be found in the recent publication of Fleck et al. ${ }^{4}$ The fuel and gasification medium (enriched air) are injected through an external mixing twin-fluid atomizer ${ }^{42}$ into the reactor of three meters in length. The walls are electrically heated to $1473 \mathrm{~K}$. It leads to a mean residence time of about 3 seconds. Thermocouples are located at different positions along the reactor to measure the axial gas temperature. Gas species profiles are also available through probe sampling. 
Three data sets are used in this work. Experiments from Fleck et al. ${ }^{15}$ were carried out with and without char in very similar operating conditions as it can be seen in Table 3 . These data sets are respectively designated Glycol and GSKS10. In GSKS10, $10 \%$ mass of solid char has been mixed with ethylene glycol. The gasification medium is expressed in Fleck et al. ${ }^{15}$ in term of volume flow rate in standard condition of temperature and pressure. The values have been converted to mass flow rate in Table 3 for a better comparison with the third data set from Fleck et al. ${ }^{4}$ These operating conditions correspond to a stoichiometric ratio of 0.47 , as gasification reactions are to proceed at low stoichiometry. However, some values are not available in these reports. In a more recent publication, another data set called REGA-glycol-T1 is provided. More details are given, such as the accuracy of the values or the reactor outlet gas phase concentration, including nitrogen but also the mass flow rate of nitrogen purge. This publication also contains a section called «Reactor balancing and consistency of experimental data», where the authors verified the global consistency. It led to the calculation of infiltration air. The value of infiltration air and nitrogen purge for the former publication from Fleck et al. ${ }^{15}$ being unknown, deviations between experimental results and simulations can be expected.

Table 3: Operating conditions

\begin{tabular}{llll}
\hline Data set & Glycol & GSKS10 & REGA-glycol-T1 \\
\hline Mass flow rate of fuel $[\mathrm{kg} / \mathrm{h}]$ & 12.4 & 12.5 & 12.56 \\
$\quad$ Solid content $[\%$ mass $]$ & 0 & 10 & 0 \\
Mass flow rate of oxygen $[\mathrm{kg} / \mathrm{h}]$ & 7.41 & 7.65 & 9.67 \\
Gasification medium $[\mathrm{kg} / \mathrm{h}]$ & 7.41 & 7.65 & 9.22 \\
Infiltration air $[\mathrm{kg} / \mathrm{h}]$ & - & - & 0.45 \\
Mass flow rate nitrogen $[\mathrm{kg} / \mathrm{h}]$ & 2.86 & 2.91 & 9.06 \\
Gasification medium $[\mathrm{kg} / \mathrm{h}]$ & 2.86 & 2.91 & 6.94 \\
Nitrogen purge $[\mathrm{kg} / \mathrm{h}]$ & - & - & 0.64 \\
Infiltration air $[\mathrm{kg} / \mathrm{h}]$ & - & - & 1.48 \\
\hline
\end{tabular}

The reactor has a cylindrical shape. The CFD mesh is made of one layer of cells of a $10^{\circ}$ 
sector of the reactor. For the test case REGA-glycol-T1, simulation was completed for the full three meters length of the reactor, because outlet results are available. However, for the test cases Glycol and GSKS10, the computation is made for the first meter of the reactor only. The one meter and 3 meters meshes count respectively 42300 and 80000 cells, consistent with the calculations of Mancini et al. ${ }^{8}$ that indicates to use roughly $10^{5}$ unstructured cells. Steady state is reached after only 100 CPU hours on an Intel(R) Xeon(R) CPU E5-2690 @ $2.90 \mathrm{GHz}$ for the simplest test case, Glycol, and after about $1200 \mathrm{CPU}$ hours for the case GSKS10. Temperature and species concentrations are monitored during the simulations and allow to determine accurately when the values reach a plateau.

\subsection{Ethylene glycol gasification}

Here, results of the test case REGA-glycol-T1 will be shown. The liquid volume fraction is represented in Fig. 6a on a log-scale. The white part corresponds to a liquid volume fraction smaller than $7.2 \cdot 10^{-8}$ and is considered negligible. The liquid volume fraction is decreasing along the axial direction due to evaporation but also due to the spray angle; the remaining liquid occupies an always larger cross-sectional area. It has been reported that ethylene glycol evaporates slowly in comparison to other fuels, such as ethanol, diesel fuel or light heating oil, as it has already been reported. ${ }^{5}$ The field of evaporation rate is displayed in Fig. 6b. The eccentric injected liquid is evaporating faster than the liquid at the center. This can be explained with the gas temperature field (see Fig. 7a). The liquid injected at the center encounters at a lower height a high temperature surrounding, delaying the evaporation. Evaporation of ethylene glycol does not start before the first two centimeters and is complete at around $50 \mathrm{~cm}$. The axial gas velocity profile is displayed in Fig. 6c. An outer recirculation zone is observed. This recirculation is essential to stabilize the flame at the burner zone. The hot syngas produced during the gasification of ethylene glycol is driven back to the jet zone where it reacts with oxygen.

The temperature field corroborates this picture (Fig. 7a). The flame temperature in the 


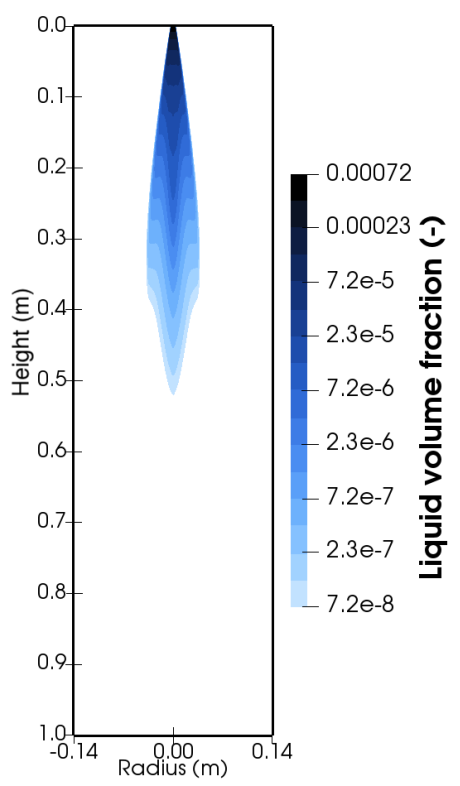

(a) Liquid volume fraction

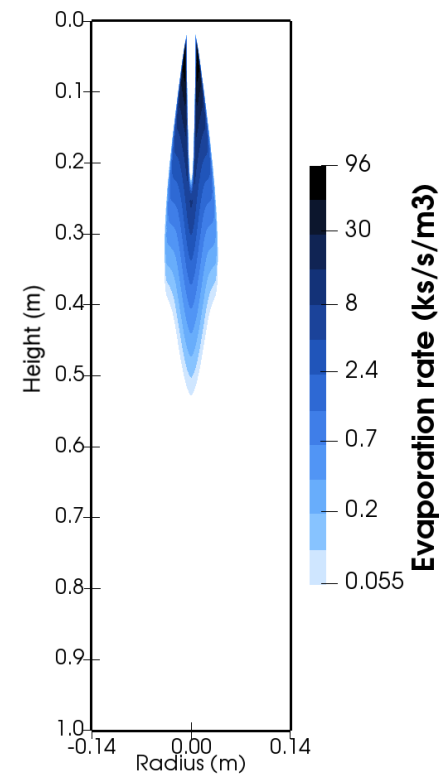

(b) Evaporation rate

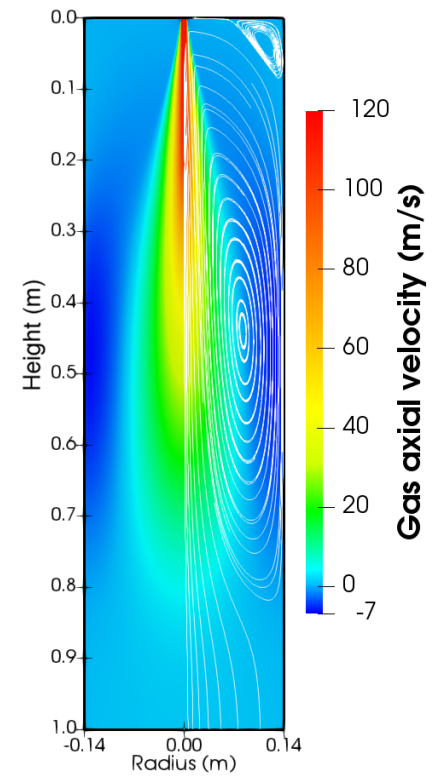

(c) Gas velocity and streamline function

Figure 6: Contours of the liquid phase volume fraction, evaporation rate, and gas velocity inside the reactor for test case REGA-Glycol-T1

first centimeters, before the ethylene glycol evaporation, is very high (2100 K) indicating a combustion assisted by the recirculated syngas. Figures $7 \mathrm{~b}-7 \mathrm{~d}$ show the mole fractions within the first meter of the reactor of the main products $\mathrm{CO}, \mathrm{CO}_{2}$ and $\mathrm{H}_{2}$. The zones of high oxidizer content correspond to the extrema in carbon dioxide concentration. On the contrary, the fuel rich zones, or off-axis regions, are favoring the production of syngas.

Quantitative results are shown in Fig. 8. The experimental values have been taken at $300 \mathrm{~mm}$ and $680 \mathrm{~mm}$ downstream of the burner. Our simulations (lines) and the experimental results (symbols) of Fleck et al. ${ }^{4}$ agree quite well. In the experiment, $\mathrm{H}_{2}, \mathrm{CO}, \mathrm{CO}_{2}$ and $\mathrm{CH}_{4}$ have been measured while $\mathrm{N}_{2}$ has been calculated by difference. The concentration values of the simulation, especially at $680 \mathrm{~mm}$ below the burner, are in excellent agreement with the experimental data. The concentration results at $300 \mathrm{~mm}$ downstream of the burner are in good agreement except for the points along the center. At this particular point, simulation shows high content of radicals. $\mathrm{H}$ radical concentration is for example of $1.5 \%$ vol while $\mathrm{O}$ radical concentration is at about $0.3 \%$ vol. The recombination of $\mathrm{H}$ to give $\mathrm{H}_{2}$ explains 


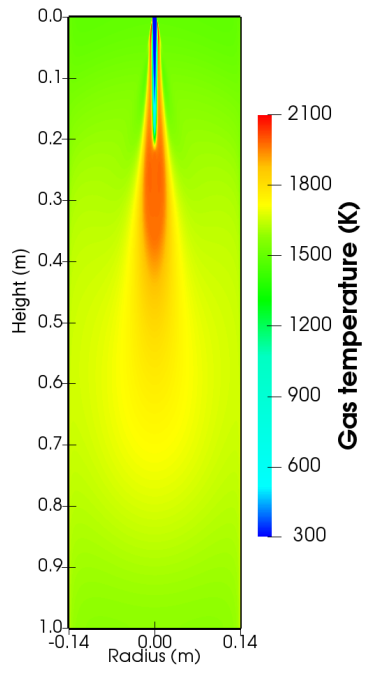

(a) Gas temperature

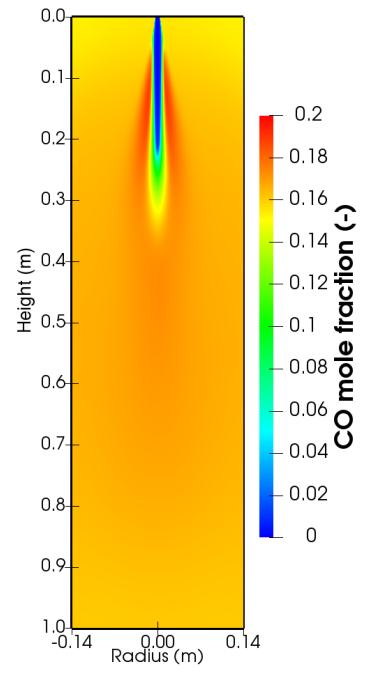

(b) $\mathrm{CO}$ mole fraction

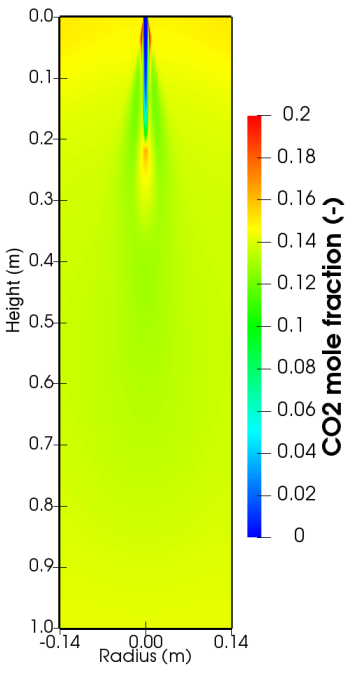

(c) $\mathrm{CO}_{2}$ mole fraction

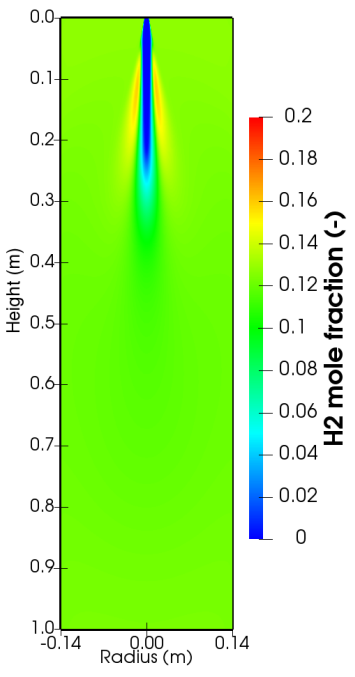

(d) $\mathrm{H}_{2}$ mole fraction

Figure 7: Temperature and main species fields for test case REGA-Glycol-T1; - Experimental data

partially the discrepancy of $\mathrm{H}_{2}$ at this position. More generally the oxidation of the fuel at very low stoichiometry happens at this location which favors $\mathrm{CH}_{4}, \mathrm{H}_{2}$ and $\mathrm{CO}$ formation to the detriment of $\mathrm{CO}_{2}$. The decomposition of the fuel into smaller species increases the molar concentration and mechanically decreases the one of $\mathrm{N} 2$.

Concerning the temperature profile (Fig. 9), the simulation agrees well with the measured data. The boundary condition for the wall temperature has been set to the experimental results given in Fig. 14 of Fleck et al., ${ }^{4}$ allowing to have a good global value for the wall temperature along the three meters of the reactor. The Dirichlet condition $T_{\text {wall }}=1473 \mathrm{~K}$ could have been chosen to reproduce the set point given to the electrical elements. However, the experimental results clearly show that the real wall temperature is higher than $T_{\text {wall }}=$ 1473 K. Similarly, a Naumann zero gradient condition could have been chosen for the temperature, which corresponds to a zero heat flux through the walls, but the heat loss in the upper corner and at the reactor outlet would have been underestimated.

The data set REGA-glycol-T1 also provides the syngas composition leaving the gasifier. The results of the simulation are given in Table 4, showing that the concentration results 


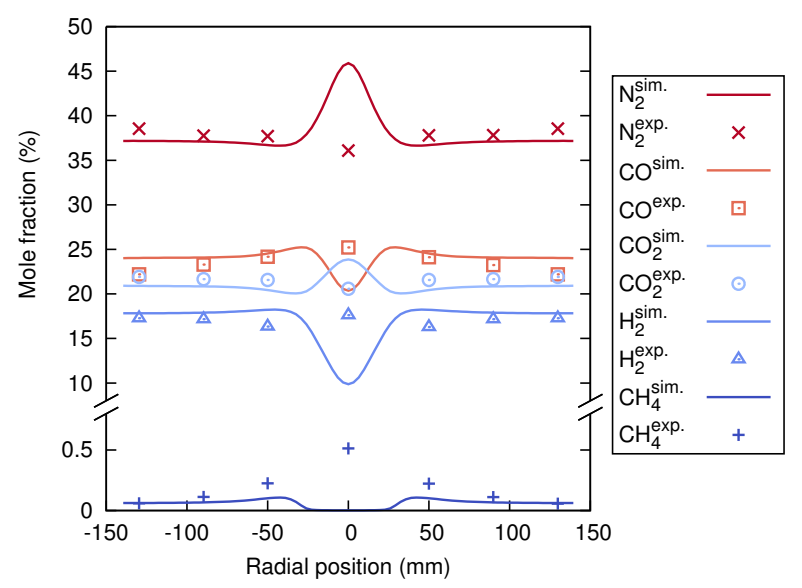

(a) $300 \mathrm{~mm}$ below the burner

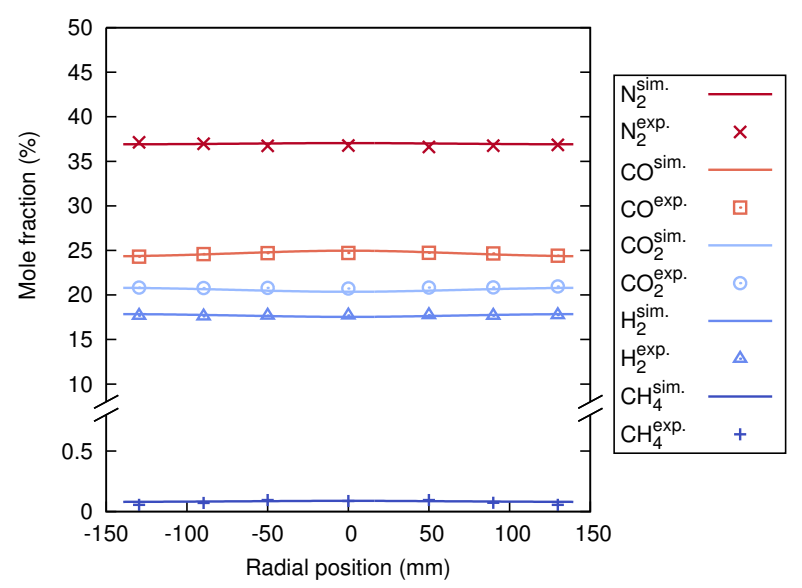

(b) $680 \mathrm{~mm}$ below the burner

Figure 8: Experimental ${ }^{4}$ and simulation composition results for ethylene glycol gasification - Data set REGA-Glycol-T1 (dry basis)

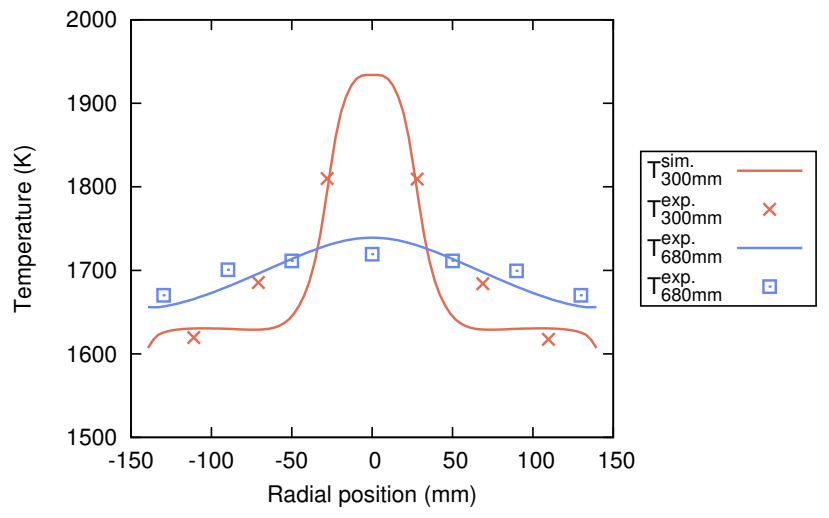

Figure 9: Experimental ${ }^{4}$ and simulation temperature results for ethylene glycol gasification - Data set REGA-Glycol-T1 
are very close to the ones obtained in the experiment.

Table 4: Syngas composition leaving REGA: data set REGA-Glycol-T1

\begin{tabular}{llll}
\hline Species & \multicolumn{2}{l}{ Experiment $[\%$ vol $]$} & Simulation [\%vol $]$ \\
\hline $\mathrm{H}_{2}$ & $12.79 \pm 0.39$ & 12.959 \\
$\mathrm{CO}$ & $14.63 \pm 0.46$ & 14.988 \\
$\mathrm{CO}_{2}$ & $14.76 \pm 0.44$ & 15.013 \\
$\mathrm{CH}_{4}$ & $0.009 \quad \pm 0.002$ & 0.038 \\
$\mathrm{H}_{2} \mathrm{O}$ & 33.08 Calc. & 32.156 \\
$\mathrm{~N}_{2}$ & 24.74 & Calc. & 24.846 \\
& & & \\
$\Sigma$ & 100.009 & 100.000 \\
\hline
\end{tabular}

Comparisons with the other published calculations ${ }^{8,9}$ of the data set REGA-Glycol-T1 can be done. These two publications being limited to pure ethylene glycol gasification, only this first part can be subject to comparison. The major difference relies obviously on the multiphase treatment, Euler/Lagrange or Euler/Euler. Particle position, velocity, temperature and size are based on the Lagrangian particle tracking method through ordinary differential equations, while the liquid phase is solved in the Euler/Euler method with transport equations for mass, momentum or energy. The evaporation modeling is nevertheless in all cases based on the Spalding's evaporation rate (equation 4 here). The RANS calculations of Mancini et al. ${ }^{8}$ have allowed the investigation of several choices for the modeling of chemistry-turbulence interaction (Eddy Dissipation or presumed PDF approach), and also the radiation scattering of droplet, but were nevertheless computed with global chemical mechanism. Concerning the calculations of Eckel et al., ${ }^{9}$ they achieved detailed description of turbulence by means of Large Eddy Simulation. This is undeniably an advantage to get a better understanding on the underlying phenomena but computationally too much expensive if case study is overseen. Their results of temperature and species show higher discrepancy than the results presented here. This can however be explained by the fact that infiltration air and nitrogen purge were not taken into account in their calculations, because these values were still unknown when the simulation was almost completed. 


\subsection{Slurry fuel gasification}

The data sets Glycol and GSKS10 are presented in this section and for the second one, four cases are studied. The first three cases for GSKS10 will allow examining the influence of the reaction rate of char pyrolysis. For all cases, a first order reaction kinetics with regard to the reactant has been chosen as well as an activation energy $E_{a}=500 \mathrm{~J} / \mathrm{mol}$. The pre-exponential factor has been varied: $k_{1}=2 \cdot 10^{11} \mathrm{~s}^{-1}$ is used for the reference case, $k_{1 / 5}=4 \cdot 10^{10} \mathrm{~s}^{-1}$ for the slow devolatilization case and $k_{5}=1 \cdot 10^{12} \mathrm{~s}^{-1}$ for the fast devolatilization case. For these three cases, the volatile content is the one deduced from the secondary pyrolysis experiment. For the $4^{\text {th }}$ case of GSKS10, the volatiles are those obtained with the data of the proximate analysis. $k_{1}$ has been used for this case.

The experimental and simulations species concentrations of ethylene glycol (Glycol, Fig. 10a) and slurry fuel (GSKS10, Fig. 10b) gasification respectively are shown in Fig. 10. It can be seen that for this test case the deviation from the experimental results is higher than for the simulation of the test case REGA-glycol-T1. This is because the infiltration air and the nitrogen purge volume flow rates are not given and therefore the stoichiometry and gas to liquid ratio are incorrectly estimated. In order to validate this statement, an additional test case has been tested. In this one, the values of infiltration air and nitrogen purge determined for REGA-Glycol-T1 have been added to the gas inlet flow rate of the Glycol test case. $0.45 \mathrm{~kg} / \mathrm{h}$ of oxygen has been added to the initial oxygen mass flow rate according to Table 3 and the total nitrogen mass flow rate accounts now for $4.98 \mathrm{~kg} / \mathrm{h}(2.86+0.64+1.48)$. As it can be seen in Fig. 10, a clear improvement is obtained for all species. The dependency on the secondary pyrolysis kinetic rate is also shown in Fig. 10b. The simulation with the lowest kinetic rate shows the closest agreement with the experimental values, while the fastest kinetic rate leads to the maximum deviation. However, these global simulation results do not distinguish between deviations due to the ethylene glycol gasification and the modeling of the solid phase. Therefore, it is more appropriate to observe the trends between the liquid gasification and the slurry gasification. The experiments show an increase of carbon 
monoxide and carbon dioxide (2\% and $1 \%$, respectively) and a decrease of hydrogen and methane (3\% and $<1 \%$, respectively). All three simulations globally follow the same trend (carbon monoxide increase; hydrogen decrease). The simulation with the mean pyrolysis kinetic rate $\left(k_{1}\right)$ shows the closest agreement.
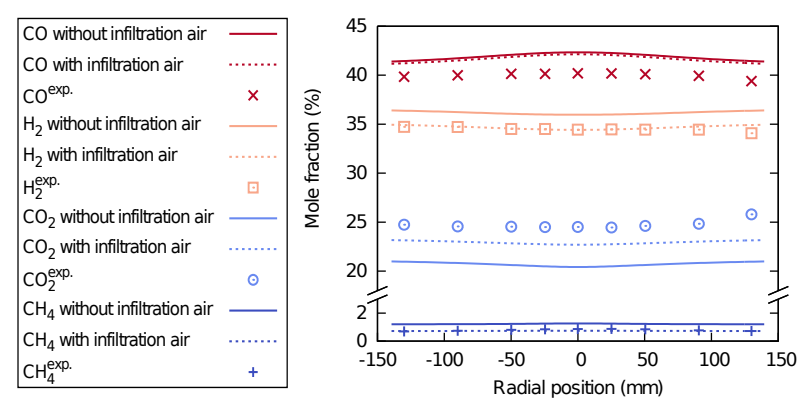

(a) Glycol results

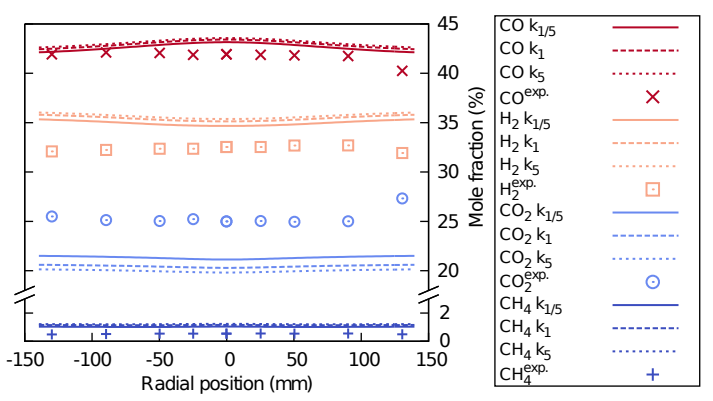

(b) GSKS10 results with different kinetic rates

Figure 10: Gasification results of Glycol (a) and of GSKS10 (b) data set; exp. from ${ }^{15}$

Figure 11 represents the contour plot of the total mass fraction of the primary char, the secondary char, and the ashes. All contours are taken from the case with the mean kinetic rate $k_{1}$. As expected, the primary char appears in the zone of liquid evaporation. It can be seen that the primary char is converted quickly into secondary char. The upper corners and the bottom region of the reactor correspond to a higher residence time and are impoverished in primary char. Due to the high momentum, secondary char and ash are mostly not present in the jet zone. In contrast to the primary char, ash occupies regions of long residence time. The total mass fraction of ash remains lower than those of char, even though ash is the final product and therefore could accumulate in the reactor. However, ashes account for $18 \%$ of the mass of solid injected in the reactor and the gasification reaction is not complete in the first meter of the reactor.

Figure 12 shows the influence of the kinetic rate of the secondary pyrolysis on the conversion of primary char along the axial direction. It can be seen that for the simulation with higher pyrolysis kinetic rate $k_{5}$ the primary char is almost completely converted after one meter, while for the slowest case $k_{1 / 5}$ only $50 \%$ of the primary char has been converted to 


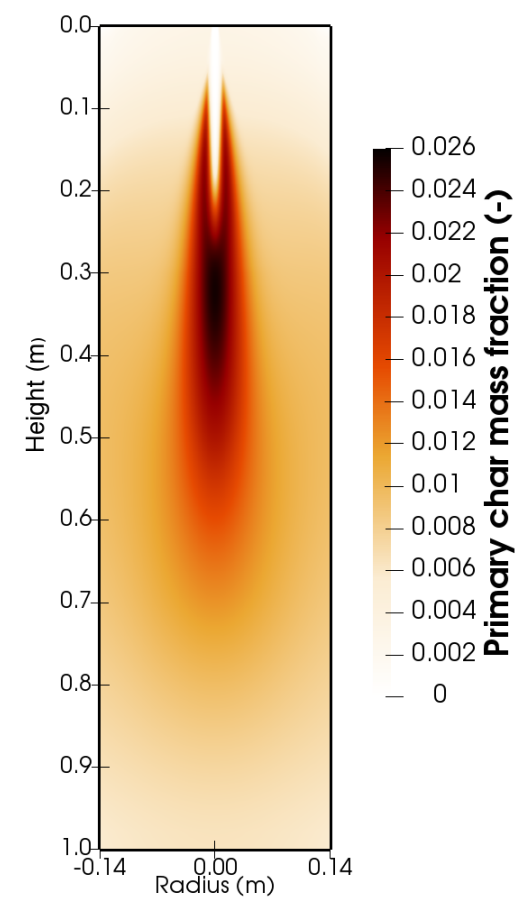

(a) Primary char

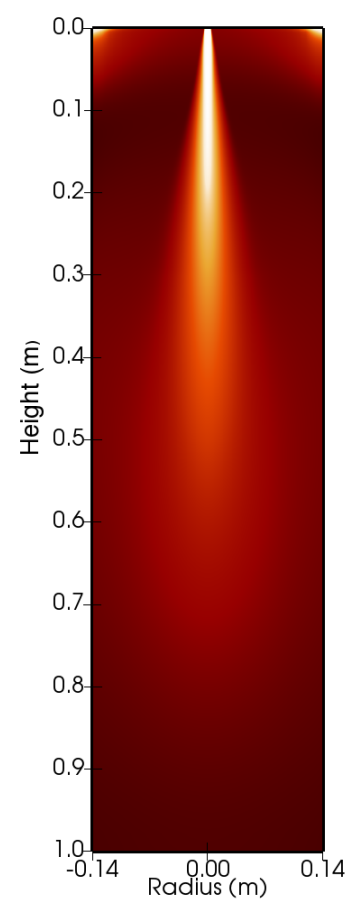

(b) Secondary char

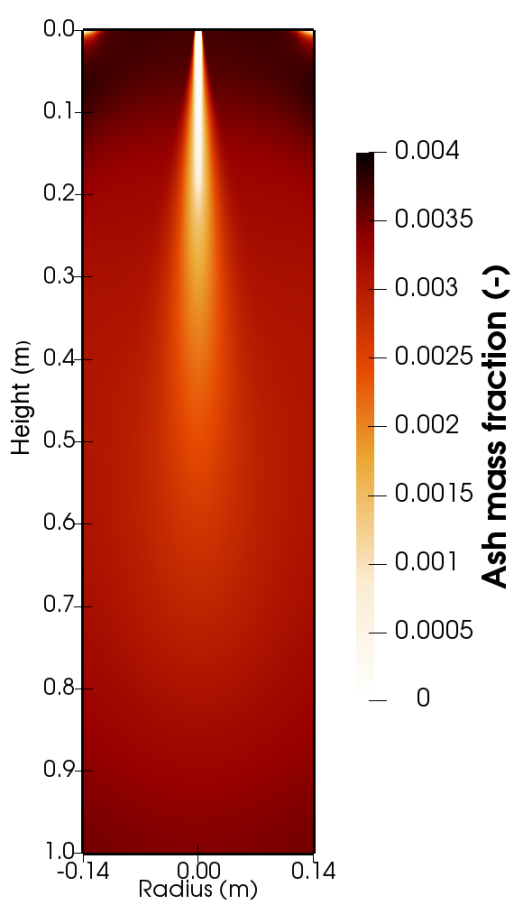

(c) Ash

Figure 11: Contours of the primary char, secondary and ash mass fraction

secondary char.

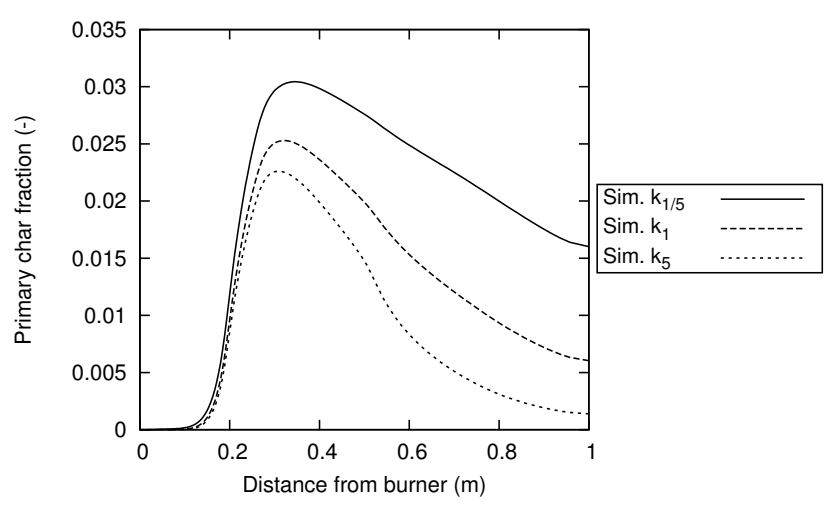

Figure 12: Primary char mass fraction along the central axis

Figure 13 shows the results for the two assumptions of volatiles that have been discussed in section 3.2. The differences remain low, especially on the carbon dioxide concentration. The simulation with the volatiles deduced from the proximate analysis has a lower carbon monoxide mass fraction and a higher hydrogen mass fraction. This can be explained by the 
elemental composition being twice as poor in carbon compared to the volatiles deduced from the pyrolysis experiment. The observation of the trends in carbon monoxide suggests that the volatiles predicted based on the second pyrolysis experiment offer a better agreement.

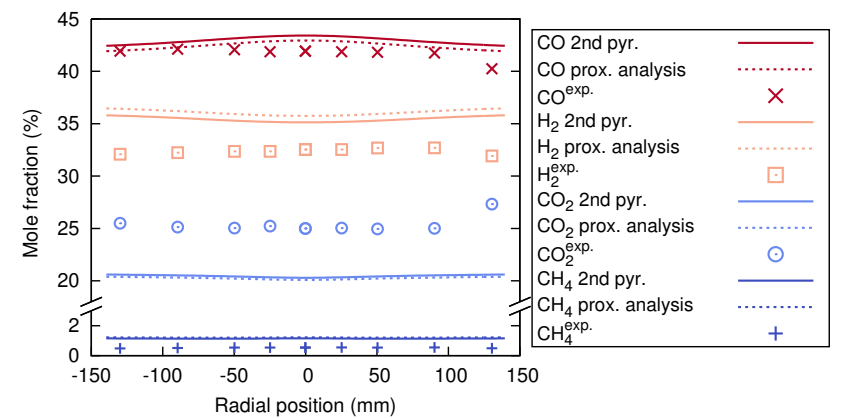

Figure 13: Slurry gasification results with different volatiles; exp. from ${ }^{15}$

\section{Conclusion and outlook}

Faced with the observation that the design and scale-up of industrial entrained-flow gasification are mainly based on experience, there is a need to develop CFD-based modeling tools. The high complexity of such high-pressure and high-temperature multiphase reactor is a challenge to achieve reliable and predictive calculations while maintaining reasonable computational costs. In an attempt to propose alternative methods, a novel approach has been proposed for the modeling of bio-slurry gasification. On the one hand, the char gasification modeling has been achieved for the first time based on the use of a sectional method, while on the other hand, the traditional Euler-Lagrange approach for the liquid fuel spray has been replaced by an Euler/Euler approach.

The multiphase Euler/Euler solver, based on the OpenFOAM open source code, has shown its ability to reproduce the ethylene glycol spray and evaporation in a 2D-RANSsimulation. This method offers a high flexibility and low computational cost. A detailed mechanism of ethylene glycol combustion has been used. The temperature and species results show a good agreement with experimental results from the REGA gasifier. 
The sectional approach for the char gasification has been adapted to the peculiarities of gasification. The so-called primary char, secondary char and ash have been grouped into individual classes that have been furthered discretized via the sectional approach. This model describes the different stages that the solid particles undergo in a gasifier, with distinct elemental compositions. The approach presented here for the char gasification is highly flexible and can be quickly adapted to other char or coal sources, thanks to the method detailed here. The approach captures well the solid mass and number distribution. However, uncertainties remain in the model, especially concerning the solid reaction rates. The results of simulation of the slurry gasification are affected by the errors on the gas/liquid ratio. The influence of devolatilization and choice of the volatile part have been studied; both being important process parameters. Further validation is necessary to reduce these uncertainties. For example, it would be interesting to validate the model on experiments with only solid particles, to avoid the influence of the errors of the liquid phase modeling.

\section{Acknowledgement}

The authors gratefully acknowledge the collaboration with Nicolaus Dahmen, Thomas Kolb and Dieter Stapf (Karlsruhe Institute of Technology) within the Helmholtz «Energy Efficiency, Materials, and Resources» Programme. Funding by the energy, combustion, and gas turbine technology program (EVG) of Deutsches Zentrum für Luft- und Raumfahrt e. V. (DLR), the German Aerospace Center, is gratefully acknowledged.

\section{References}

(1) Higman, C. Annual International Pittsburgh Coal Conference 2013, PCC 2013, 30, $226-247$.

(2) Ryzhkov, A. F.; Bogatova, T. F.; Lingyan, Z.; Osipov, P. V. Thermal Engineering 2016, 63, 791-801. 
(3) Dahmen, N.; Dinjus, E.; Kolb, T.; Arnold, U.; Leibold, H.; Stahl, R. Environmental Progress 65 Sustainable Energy 2012, 31, 176-181.

(4) Fleck, S.; Santo, U.; Hotz, C.; Jakobs, T.; Eckel, G.; Mancini, M.; Weber, R.; Kolb, T. Fuel 2018, 217, 306-319.

(5) Kolb, T.; Aigner, M.; Kneer, R.; Mueller, M.; Weber, R.; Djordjevic, N. Journal of the Energy Institute 2016, 89, 485-503.

(6) Kathrotia, T.; Naumann, C.; Osswald, P.; Koehler, M.; Riedel, U. Combustion and Flame 2017, 179, 172-184.

(7) Hafner, S.; Rashidi, A.; Baldea, G.; Riedel, U. Combustion Theory and Modelling 2011, $15,517-535$.

(8) Mancini, M.; Alberti, M.; Dammann, M.; Santo, U.; Eckel, G.; Kolb, T.; Weber, R. Fuel 2018, 225, 596-611.

(9) Eckel, G.; Clercq, P. L.; Kathrotia, T.; Saenger, A.; Fleck, S.; Mancini, M.; Kolb, T.; Aigner, M. Fuel 2018, 223, 164-178.

(10) Hill, S. C.; Smoot, L. D. Energy \& Fuels 1993, 7, 874-883.

(11) Kumar, M.; Ghoniem, A. F. Energy \& Fuels 2012, 26, 464-479.

(12) Abani, N.; Ghoniem, A. F. Fuel 2013, 104, 664-680, 10th Japan/China Symposium on Coal and C1 Chemistry.

(13) Ma, J.; Zitney, S. E. Energy 65 Fuels 2012, 26, 7195-7219.

(14) Warnatz, J.; Maas, U.; Dibble, R. Combustion: Physical and Chemical Fundamentals, Modeling and Simulation, Experiments, Pollutant Formation; 1996.

(15) Fleck, S.; Hotz, C.; Stoesser, P.; Kolb, T. 2\%. Deutscher Flammentag 2015, VDIBerichte 2267, 207-217. 
(16) Vicente, W.; Ochoa, S.; Aguillâşn, J.; Barrios, E. Applied Thermal Engineering 2003, 23, 1993-2008.

(17) http://openfoam.org, [online]. 2018.

(18) Spalding, D. Symposium (International) on Combustion 1953, 4, 847-864, Fourth Symposium (International) on Combustion.

(19) Abramzon, B.; Sirignano, W. International Journal of Heat and Mass Transfer 1989, 32, 1605-1618.

(20) Hubbard, G.; Denny, V.; Mills, A. International Journal of Heat and Mass Transfer 1975, 18, 1003-1008.

(21) Clift, R.; Grace, J.; Weber, M. Bubbles, Drops, and Particles; Dover Civil and Mechanical Engineering Series; Dover Publications, 2005.

(22) Methling, T.; Braun-Unkhoff, M.; Riedel, U. Combustion Theory and Modelling 2017, 21, 503-528.

(23) Jones, W.; Launder, B. International Journal of Heat and Mass Transfer 1972, 15, 301-314.

(24) Cheng, P. AIAA Journal 1964, 2, 1662-1664.

(25) Bhave, A.; Kraft, M. SIAM Journal on Scientific Computing 2004, 25, 1798-1823.

(26) Gelbard, F.; Seinfeld, J. H. Journal of Colloid and Interface Science 1980, 78, 485-501.

(27) Pope, C. J.; Howard, J. B. Aerosol Science and Technology 1997, 27, 73-94.

(28) Blacha, T.; Domenico, M. D.; Gerlinger, P.; Aigner, M. Combustion and Flame 2012, 159, 181-193.

(29) Eberle, C.; Gerlinger, P.; Aigner, M. Combustion and Flame 2017, 179, 63-73. 
(30) Lin, T.; Goos, E.; Riedel, U. Fuel Processing Technology 2013, 115, 246-253.

(31) Netzell, K.; Lehtiniemi, H.; Mauss, F. Proceedings of the Combustion Institute 2007, $31,667-674$.

(32) D’Anna, A. Energy \& Fuels 2008, 22, 1610-1619.

(33) Saggese, C.; Sánchez, N. E.; Frassoldati, A.; Cuoci, A.; Faravelli, T.; Alzueta, M. U.; Ranzi, E. Energy \&f Fuels 2014, 28, 1489-1501.

(34) Domenico, M. D.; Gerlinger, P.; Aigner, M. Combustion and Flame 2010, 157, 246-258.

(35) Blacha, T.; Di Domenico, M.; Koehler, M.; Gerlinger, P.; Aigner, M. AIAA Aerospace Sciences Meeting Including the New Horizons Forum and Aerospace Exposition 2011, 49, 114-124.

(36) Eberle, C.; Gerlinger, P.; Aigner, M. AIAA Aerospace Sciences Meeting 2017, 55, 1785.

(37) Richter, H.; Granata, S.; Green, W. H.; Howard, J. B. Proceedings of the Combustion Institute 2005, 30, 1397-1405.

(38) Moss, J.; Aksit, I. Proceedings of the Combustion Institute 2007, 31, 3139-3146.

(39) Dahmen, N. Personal communication

(40) Pfitzer, C.; Dahmen, N.; Weirich, F.; Troeger, N.; Sauer, J. Proceedings 22nd European Biomass Conference and Exhibition, Hamburg, June 23-26 2014, 22, 1258-1262.

(41) Heintzenberg, J. Aerosol Science and Technology 1994, 21, 46-48.

(42) Jakobs, T.; Djordjevic, N.; Fleck, S.; Mancini, M.; Weber, R.; Kolb, T. Applied Energy 2012, 93, 449-456.

(43) Klose, W.; Woelki, M. Fuel 2005, 84, 885-892. 
(44) Schneider, C.; Stoesser, P.; Rincon, S.; Kolb, T. 28. Deutscher Flammentag 2017, VDI-Berichte 2302, 331-343.

(45) Zhang, L.; Xu, C. C.; Champagne, P. Energy Conversion and Management 2010, 51, 969-982.

(46) Morgano, M. T.; Leibold, H.; Richter, F.; Seifert, H. Journal of Analytical and Applied Pyrolysis 2015, 113, 216-224.

(47) Stoesser, P.; Ruf, J.; Gupta, R.; Djordjevic, N.; Kolb, T. Energy \& Fuels 2016, 30, 6448-6457.

(48) Laurendeau, N. M. Progress in Energy and Combustion Science 1978, 4, 221-270.

(49) Bews, I.; Hayhurst, A.; Richardson, S.; Taylor, S. Combustion and Flame 2001, 124, 231-245.

(50) Blasi, C. D. Progress in Energy and Combustion Science 2009, 35, 121-140.

(51) Mueller, A.; Haustein, H. D.; Stoesser, P.; Kreitzberg, T.; Kneer, R.; Kolb, T. Energy \& Fuels 2015, 29, 6717-6723.

(52) Lee, A.; Law., C. Combustion and flame 1991, 85, 77-93. 